\title{
POTENTIOSTATIC TRANSIENTS RELATED TO THE ELECTROLYTIC OXIDATION OF KSCN AND MIXTURES OF NaSCN + KSCN MELTS ON POLYCRYSTALLINE PLATINUM
}

\author{
V.D. VÁSQUEZ MOLL and A.J. ARVIA \\ Instututo de Investigaciones Fisicoqumicas Tebricas y Aplicadas, INIFTA, Casilla de Correo I6, Sucursal 4, \\ 1900 La Plata (Argentina)
}

(Received 28th March 1985)

\section{ABSTRACT}

Potentiostatic transients related to the electrolytic oxidation of molten thiocyanate (KSCN and $\mathrm{KSCN}+\mathrm{NaSCN}, 0.7: 0.3 \mathrm{~mol} / \mathrm{mol}$ ) on polycrystalline $\mathrm{Pt}$ obtained in the $168-290^{\circ} \mathrm{C}$ range are interpreted in terms of a nucleation and growth mechanism under diffusion control which involves the formation of two different produets constituting the passivating anodic layer. The different adjustable parameters are compatible with the possible molecular structure of the anodic layer.

\section{INTRODUCTION}

Molten KSCN and its mixtures with $\mathrm{NaSCN}$ are low melting point salt systems which are stable liquids in the temperature range from the $\mathrm{mp}$ up to $290^{\circ} \mathrm{C}[1,2]$. The electrolytic oxidation of $\mathrm{SCN}^{-}$ion in thiocyanate melts results in the primary formation of thiocyanate radicals ( $\mathrm{SCN}^{*}$ ) on $\mathrm{Pt}$ which either polymerize to chemically stable parathiocyanogen, $(\mathrm{SCN})_{x}[3-7]$, or interact with $\mathrm{SCN}^{-}$ions in the melt to yield trithiocyanate ion, $(\mathrm{SCN})_{3}^{-}$. The latter is further oxidized to polytrithiocyanogen, $\left[(\mathrm{SCN})_{3}\right]_{x}$, which is chemically unstable [8]. Other authors found the reaction to give sulphur and cyanogen $[1,2]$. The formation of different products depends to a great extent on the working temperature. Thus, parathiocyanogen is the main product at low temperatures $\left(T<250^{\circ} \mathrm{C}\right)$ while the relative yields of sulphur and cyanogen increase at higher temperatures $\left(T>250^{\circ} \mathrm{C}\right)$. In both cases passivation of the $\mathrm{Pt}$ anode by a poorly electrical conducting anodic layer is observed. The same type of passivity onset is also produced by anodizing a $\mathrm{Pt}$ electrode in non-aqueous KSCN solutions [9].

Previous studies of the electrolytic oxidation of $\mathrm{SCN}^{-}$in thiocyanate melts focused on the identification of reaction products [1-6], the interpretation of the overall process in terms of possible electrochemical and chemical reactions [4-7], and the determination of its electrical characteristics and effect of light $[8,10]$.

In the present paper we attempt to interpret the kinetics of the anodic layer 
formation from the characteristics of the potentiostatic current transients in terms of a nucleation and growth mechanism. This approach has been successfully applied to many electrochemical reactions involving either the formation or the removal of a solid phase $[11,12]$.

EXPERIMENTAL

The potentiostatic current transients were recorded as described in previous publications [5], using a conventional three-compartment electrolysis cell. Polycrystalline $\mathrm{Pt}$ wires of $0.47 \mathrm{~cm}^{2}$ apparent area were used as working electrodes. Each electrode was first cleaned either by immersion in a 1:1 $\mathrm{H}_{2} \mathrm{SO}_{4}+\mathrm{HNO}_{3}$ mixture or by polishing with an alumina + water suspension, then rinsed with triply distilled water, and finally dried in a stream of air. A clean electrode was used for each run. A large $\mathrm{Pt}$ plate counter-electrode mounted in a separated compartment was employed. It was connected to the rest of the electrolysis cell by means of a fritted glass disk.

The potential of the working electrode was measured against a Pt electrode placed into the third compartment of the electrolysis cell containing the same electrolyte melt. The potential of this electrode was very stable and reproducible. As there is no initial potential difference between the working electrode and the platinum electrode, the rest potential of the working electrode was taken as zero.

Either molten AR (Riedel de Häen and Carlo Erba) KSCN (mp $177^{\circ} \mathrm{C}$ ) or $\mathrm{KSCN}+\mathrm{NaSCN}(0.7: 0.3 \mathrm{~mol} / \mathrm{mol}), 143-197^{\circ} \mathrm{C}$ range [13], was used as electrolyte. Runs were made in the $168-290^{\circ} \mathrm{C}$ range. Potential steps $\left(E_{\mathrm{s}}\right)$ were applied to the working electrode by means of switching mercury-wetted relays and the corresponding current transients were photographed from a fast rise time $(0.35 \mu \mathrm{s})$ oscilloscope screen.

\section{RESULTS}

In the entire temperature range, the potentiostatic current transients run in the potential step range from $0.40 \mathrm{~V} \leqslant E_{\mathrm{s}} \leqslant 0.55 \mathrm{~V}$ (Fig. 1) exhibit a very fast initial current jump, of the order of ms, which is related to the charging of the electrical double layer. Then the current increases to reach a maximum $\left(I_{\mathrm{M}}\right)$ value in about 0.1-1 s range $\left(t_{M}\right)$ and later it shows a sigmoid-like decrease to zero current. The value of $I_{\mathrm{M}}$ increases and that of $t_{\mathrm{M}}$ decreases depending on $E_{\mathrm{s}}$. For a constant $E_{\mathrm{s}}$ value, $I_{\mathrm{M}}$ increases as the temperature increases. The anodic charge $\left(Q_{\mathrm{a}}\right)$ evaluated from the current transients is practically constant and independent of both $E_{\mathrm{s}}$ and $T$, within the ranges covered by the present work. In this case, the electrical double-layer charge is negligible in comparison with the faradaic charge related to the formation of the anodic layer. In the entire range of temperature, the reproducibility of the current transients is very good. Likewise, no increase of roughness in the Pt electrode area, which might be caused by corrosion of the metal in the melt, was detected. 
293

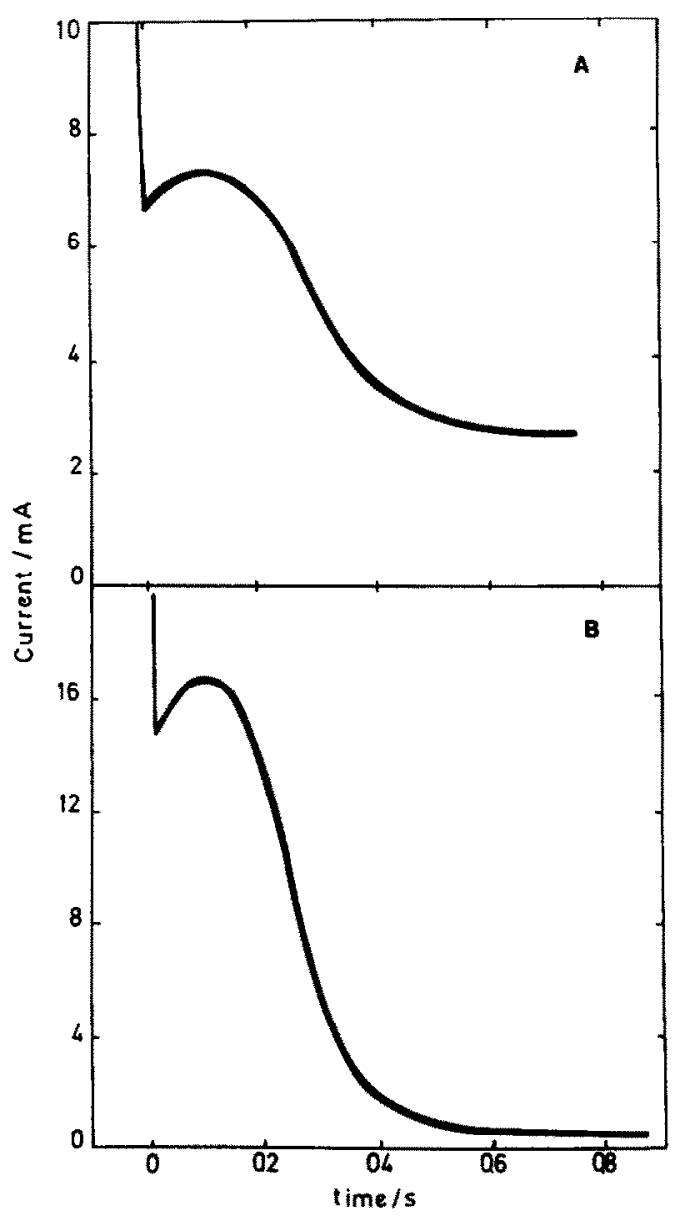

Fig. 1. Potentiostatic current transients. (A) Molten $\mathrm{KSCN}, 192^{\circ} \mathrm{C} ; E_{\mathrm{s}}=0.490 \mathrm{~V}$; (B) molten $\mathrm{KSCN}$, $255^{\circ} \mathrm{C} ; E_{\mathrm{s}}=0.490 \mathrm{~V}$.

DISCUSSION

Processes involved in the electro-oxidation of molten $\mathrm{SCN}^{-}$ion

The characteristics of the potentiostatic current transients suggest that the formaion of the anodic layer resulting from the electro-oxidation of molten $\mathrm{SCN}^{-}$ion is governed by a nucleation and growth mechanism. However, a straightforward application of simple nucleation and growth mechanisms, such as either a nucleation and growth mechanism under charge-transfer control or a competitive adsorption-nucleation and growth mechanism [5,7], fails to explain the kinetics of the electrochemical process in the entire range of both $E_{\mathrm{s}}$ and $T[5,6]$. Therefore, it is 
reasonable to attempt an explanation of the results starting from the fact that molten $\mathrm{SCN}^{-}$ion electro-oxidation undergoes parallel reaction pathways [8], yielding two different solid phases. Kinetic studies on the electrochemical oxidation of molten $\mathrm{KSCN}$ indicate that the yellow reaction product consists of two main substances, $(\mathrm{SCN})_{x}$ and $\left[(\mathrm{SCN})_{3}\right]_{x}$, whose concentration ratio depends on the electroformation conditions. Hence, the potentiostatic current transients should involve at least two different processes competing to cover the electrode surface. One of the simplest ways to represent the electrochemical formation of the reaction products from the discharge of $\mathrm{SCN}^{-}$ions is by two reaction pathways, each one involving a series of reactions with the participation of polymeric units:

Reaction (I)

$\mathrm{SCN}^{-} \rightleftarrows(\mathrm{SCN})^{\cdot}+e^{-}$

$x\left(\mathrm{SCN}^{*}\right) \rightarrow(\mathrm{SCN})_{x}(\mathrm{~s})$

Reaction (II)

$\mathrm{SCN}^{-} \rightleftarrows\left(\mathrm{SCN}^{*}\right)+e^{-}$

$2\left(\mathrm{SCN}^{-}\right)+\mathrm{SCN}^{-} \rightarrow(\mathrm{SCN})_{3}+e^{-}$

$x^{\prime}(\mathrm{SCN})_{3} \rightarrow\left[(\mathrm{SCN})_{3}\right]_{x^{\prime}}(\mathrm{s})$

The initial discharge of $\mathrm{SCN}^{-}$ion is associated with a relatively fast and reversible reaction, as is indicated by previous results obtained in various different systems $[9,14]$. The rates of the following stages, either (Ib) or (IIb) and (IIc), imply the formation of new solid phases on the electrode surfaces. The initial formation of $(\mathrm{SCN})_{x}$ which is considered to be the most stable reaction product is probably faster than the formation of the $\left[(\mathrm{SCN})_{3}\right]_{x^{\prime}}$ species. The corresponding processes can be analysed in terms of a nucleation and growth mechanism. This mechanism establishes that the formation of a new phase depends on the random distribution of active sites at the surface and on the probability of transforming an active site into a growing nucleus [11,12].

\section{Combined nucleation and growth mechanism under diffusion control}

It is reasonable to assume that a polycrystalline metal surface offers different kinds of active sites and that the rate of conversion of active sites into growing nuclei is also different at each kind of active site. In the simplest case, one considers the existence of only two different sites (I and II), where reaction (I) is favoured at sites I, whereas reaction (II) takes place at sites II. It is further assumed that reaction (I) involves an instantaneous 2D nucleation and growth mechanism while reaction (II) implies a progressive 2D nucleation and growth process, both under diffusion control [15]. Therefore, as the anodic process proceeds, the anodic products progressively cover the electrode surface.

The rate equation for $(\mathrm{SCN})_{x}$ formation in accordance with an instantaneous $2 \mathrm{D}$ 
nucleation and growth under diffusion control mechanism as a single process is given by $[11,12]$ :

$I_{\mathrm{I}}=q_{\mathrm{m}} \pi N_{0}^{\mathrm{I}} \lambda^{2} D \exp \left(-\pi \lambda^{2} D N_{0}^{\mathrm{l}} t\right)$

where $I_{\mathrm{I}}$ is the current at time $t$, associated with the electroformation of $(\mathrm{SCN})_{x} ; q_{\mathrm{m}}$ is the anodic charge required to complete the coverage of the electrode surface; $N_{0}^{1}$ is the total number of sites of type $I$; and $\lambda$ is a constant related to the nucleus growth which is given by the relationship [15]:

$\lambda^{2} \exp \left(\lambda^{2}\right) \operatorname{erf}\left(-\lambda^{2}\right)=\left[c_{0}-c_{\mathrm{s}}\left(E_{\mathrm{s}}\right)\right] \frac{M}{\rho}$

$c_{0}$ and $c_{\mathrm{s}}$ denote the concentrations of the reacting species at the bulk of the melt and at the electrode surface, respectively. $D$ and $M$ correspond to the diffusion coefficient and molar mass of the diffusing species and $\rho$ is taken as the density of the melt.

The rate equation for $\left[(\mathrm{SCN})_{3}\right]_{x^{\prime}}$ electroformation under a $2 \mathrm{D}$ progressive nucleation and growth mechanism as a single process is:

$I_{11}=q_{\mathrm{m}} \pi \lambda^{2} D A t \exp \left(-\pi \lambda^{2} D A t^{2} / 2\right)$

where the subscript II refers to reaction (II) and $A$ is the rate of nucleation at sites II. Equations (1) and (3) imply the same $\lambda D^{1 / 2}$ product.

For the anodic process where both $(\mathrm{SCN})_{x}$ and $\left[(\mathrm{SCN})_{3}\right]_{x^{\prime}}$ are produced simultaneously, the fraction of surface $\left(S^{\prime}\right)$ which is covered at any instant can be obtained by extending Avrami's equation to the two reaction products through the expression [16-18]:

$S^{\prime}=1-\exp \left[-\left(S_{\text {ext.I }}+S_{\text {ext.,II }}\right)\right]$

where $S_{\text {ext,I }}$ and $S_{\text {ext,II }}$ denote the fraction of the surface which is covered by either $(\mathrm{SCN})_{x}$ or $\left[(\mathrm{SCN})_{3}\right]_{x^{\prime}}$ nuclei which are growing without overlapping. Then, the overall instantaneous current expression is:

$I=q_{\mathrm{m}} \frac{\mathrm{d} S^{\prime}}{\mathrm{d} t}=q_{\mathrm{m}} \exp \left[-\left(S_{\mathrm{ext}, \mathrm{I}}+S_{\mathrm{ext}, \mathrm{II}}\right)\right] \frac{\mathrm{d}\left(S_{\mathrm{ext}, \mathrm{I}}+S_{\mathrm{ext}, \mathrm{II}}\right)}{\mathrm{d} t}$

where:

$S_{\text {ext. I }}+S_{\text {ext.II }}=\pi \lambda^{2} D N_{0}^{\mathrm{L}} t+\pi \lambda^{2} D A t^{2} / 2=P_{2} t+P_{3} t^{2}$

Then, eqn. (5) becomes:

$I=P_{1}\left[P_{2}+2 P_{3} t\right] \exp \left[-\left(P_{2} t+P_{3} t^{2}\right)\right]$

where $P_{1}=q_{\mathrm{m}}$

Experimental results expressed in terms of current densities referred to the geometric electrode area are successfully represented by eqn. (7) in the entire range of $E_{\mathrm{s}}$ and $T$ covered in the present work (Fig. 2), using the set of parameters listed in Table 1. 


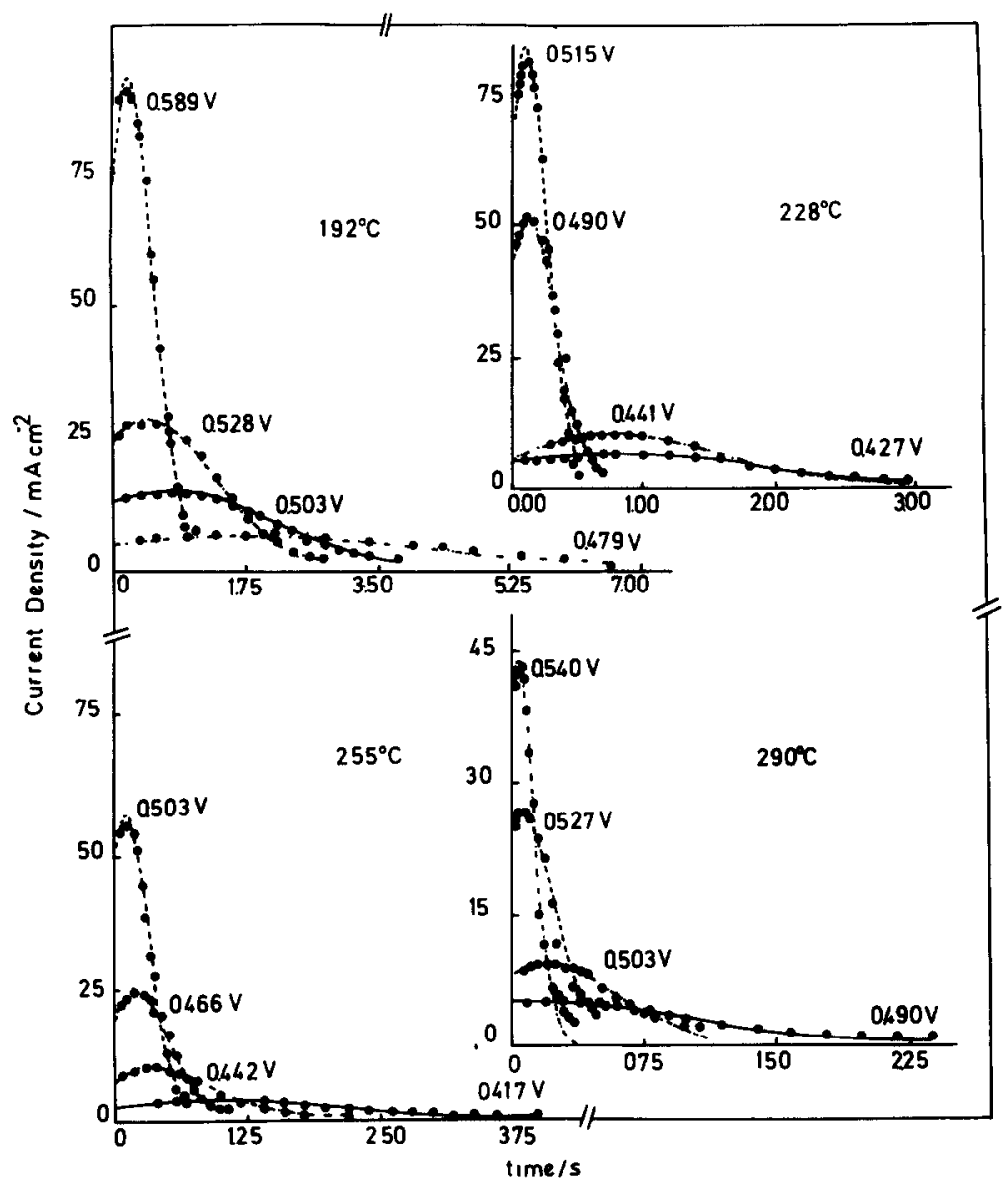

Fig. 2. Potentiostatic current transients obtained at different $E_{\mathrm{s}}$ and temperatures as indicated in the figure. Molten KSCN. The current transients indicated by the different traces were computed from eqn. (7).

\section{Estimation of physicochemical parameters}

The adjustable parameters given in Table 1 contain information about the mechanism of the anodic process at the molecular level. Thus, according to the theory $[11,12]$, the parameter $P_{3}$, which is related to the rate nucleation of $\left[(\mathrm{SCN})_{3}\right]_{x^{\prime}}$ at a constant $T$, should depend on $E_{\mathrm{s}}$ in the following way:

$\ln P_{3}=a^{\prime}-b^{\prime} / E_{\mathrm{s}}$

where

$a^{\prime}=\ln \left(Z \pi \lambda^{2} D / 2\right) \quad$ and $\quad b^{\prime}=\pi M \sigma_{1}^{2} h N_{0} / z F p R T$ 
TABLE 1

Parameters used in eqn (7) at different temperatures

\begin{tabular}{lllll}
\hline$T /^{\circ} \mathrm{C}$ & $E_{\mathrm{s}} / \mathrm{V}$ & $P_{1} / \mathrm{mC} \mathrm{cm}^{-2}$ & $P_{2} / \mathrm{s}^{-1}$ & $P_{3} / \mathrm{s}^{-2}$ \\
\hline 168 & 0.435 & 28.6 & 0.456 & 0.192 \\
168 & 0.466 & 60.1 & 0.301 & 0.379 \\
168 & 0.497 & 70.5 & 0.185 & 0.761 \\
168 & 0.528 & 89.2 & 0.262 & 1.77 \\
192 & & & 0.151 & 0.044 \\
192 & 0.479 & 32.3 & 0.332 & 0.155 \\
192 & 0.503 & 36.9 & 0.495 & 0.381 \\
192 & 0.528 & 45.7 & 1.06 & 2.61 \\
218 & 0.589 & 60.4 & 0.285 & 0.219 \\
218 & & & 0.667 & 1.07 \\
218 & 0.417 & 8.51 & 1.16 & 3.00 \\
218 & 0.442 & 10.2 & 2.06 & 6.91 \\
228 & 0.466 & 15.0 & & 0.218 \\
228 & 0.503 & 22.0 & 0.336 & 0.391 \\
228 & & 14.3 & 0.289 & 6.90 \\
228 & 0.429 & 17.9 & 1.97 & 11.4 \\
255 & 0.441 & 19.9 & 2.47 & 0.347 \\
255 & 0.490 & 25.3 & 0.525 & 1.52 \\
255 & 0.515 & 5.73 & 0.796 & 13.5 \\
255 & 0.417 & 11.0 & 2.87 & 43.1 \\
290 & 0.442 & 12.4 & 4.44 & 0.218 \\
290 & 0.479 & 15.6 & 0.732 & 1.60 \\
290 & 0.503 & & 1.64 & 3.50 \\
290 & 0.490 & 6.08 & 2.98 & 4.5 \\
\hline & 0.503 & 8.18 & 4.90 &
\end{tabular}

$Z$ is the frequency factor, $h$ corresponds to the thickness of the anodic layer, and $N_{0}$ is Avogadro's constant. Equation (8) predicts a linear $\ln P_{3}$ vs. $1 / E_{\mathrm{s}}$ relationship. Values of $a^{\prime}$ and $b^{\prime}$ (Table 2) were obtained by fitting $P_{3}$ vs. $E_{\mathrm{s}}$ functions. Both $a^{\prime}$ and $b^{\prime}$ increase with temperature.

TABLE 2

Parameters related to the rate of nucleation at different $E_{\mathrm{s}}$ and temperatures

\begin{tabular}{llcll}
\hline$T)^{\circ} \mathrm{C}$ & $a^{\prime}$ & $b^{\prime} / \mathrm{V}$ & $x_{1}{ }^{\mathrm{a}}$ & $x_{2}{ }^{\mathrm{b}}$ \\
\hline 192 & 18.2 & 10.1 & 0.479 & 0.589 \\
218 & 20.7 & 9.22 & 0.417 & 0.515 \\
228 & 23.8 & 10.8 & 0.405 & 0.527 \\
255 & 29.2 & 12.8 & 0.405 & 0.503 \\
290 & 58.9 & 29.5 & 0.466 & 0.540 \\
\hline
\end{tabular}

$a E_{\mathrm{s}}$.

$\mathrm{b} \geqslant E_{s}$. 
According to this model, the electroformation of the anodic layer implies two-dimensional polymer units, and the slope $b^{\prime}$ should be related both to $\Delta G^{*}$, the activation energy for the formation of a critical nucleus according to the expression:

$\Delta G^{*}=b^{\prime} R T / N_{0} E_{\mathrm{s}}$

and to $g^{*}$, the number of molecules at equilibrium when the critical nucleus condition is attained. $g^{*}$ is given approximately by:

$g^{*}=b^{\prime} R T / z F E_{\mathrm{s}}^{2}$

The average height $(h)$ of the critical nucleus can be estimated, assuming a cylindrical array made of linear polymeric units, from:

$h=g^{*} \delta$

where $\delta$ denotes the length of a molecular unit. From eqns. (8) and (10), the following equation is obtained:

$\delta=(z F)^{2} \rho_{\mathrm{c}} E_{\mathrm{s}}^{2} / \pi M_{\mathrm{u}} \sigma_{1}^{2} N_{0}$

where $M_{\mathrm{u}}$ and $\rho_{\mathrm{c}}$ are the molar mass and density of the polymeric unit, respectively.

On the other hand, the charge density for completing the polymeric layer results from $P_{1}$ by assuming that the covering efficiency of $(\mathrm{SCN})_{x}$ and $\left[(\mathrm{SCN})_{3}\right]_{x}$, are the same $\left(x \simeq x^{\prime}\right)$. In this case, $q_{\mathrm{m}}$ can be given approximately by the expression:

$q_{\mathrm{m}}=x F \rho_{\mathrm{c}} h^{\prime} / x M_{\mathrm{u}}$

where $h^{\prime}$ represents the average length of the polymeric chain forming the layer. Each polymeric chain is assumed to consist of $\omega$ linear polymeric units $\left(h^{\prime}=\omega h\right)$. Therefore, taking into account eqn. (13), we obtain:

$\omega=q_{\mathrm{m}} M_{\mathrm{u}} / \rho_{\mathrm{c}} F h$

Otherwise, the expression of $\lambda$ for uni-directional diffusion [11] is:

$\lambda=\left(2 M_{\mathrm{u}} c_{0} / \pi^{1 / 2} \rho\right)=\left(2 / \pi^{1 / 2}\right)$

\section{TABLE 3}

Kinetic and thermodynamic parameters estimated from the nucleation and growth model applied to anodic layer formation at $E_{\mathrm{s}}=0.479 \mathrm{~V}$ and different temperatures a

\begin{tabular}{llllccccc}
\hline$T /{ }^{\circ} \mathrm{C}$ & $\begin{array}{l}M \sigma_{1}^{2} h / \mathrm{grg}^{2} \\
\mathrm{~mol}^{-1} \mathrm{~cm}^{-3}\end{array}$ & $\begin{array}{l}10^{12} \Delta G^{*} / \mathrm{erg} \\
\text { molecule }\end{array}$ & $\begin{array}{l}g^{*} / \\
\text { molecule }\end{array}$ & $\begin{array}{l}10^{-3} N_{0}^{1} / \\
\mathrm{cm}^{-2}\end{array}$ & $\begin{array}{l}10^{-3} A / \\
\mathrm{cm}^{-2} \mathrm{~s}^{-1}\end{array}$ & $\begin{array}{l}<q_{\mathrm{m}}>/ \\
\mathrm{mC} \mathrm{cm}^{-2}\end{array}$ & $\begin{array}{l}h / \\
\mathrm{nm}\end{array}$ & $\omega$ \\
\hline 192 & 0.399 & 1.36 & $\sim 2$ & 3.79 & 2.18 & 46.8 & 1.68 & 252 \\
218 & 0.384 & 1.31 & -2 & 29.3 & 141 & 15.2 & 1.62 & 85 \\
228 & 0.459 & 1.57 & -2 & 36.0 & 253 & 18.7 & 1.93 & 87 \\
255 & 0.571 & 1.95 & -3 & 71.8 & 676 & 9.1 & 2.40 & 34 \\
290 & 1.41 & 4.79 & -6 & 7.54 & 2.76 & 8.1 & 5.93 & 12 \\
\hline
\end{tabular}

"Values of $h$ and $\omega$ were estimated on the basis of $(\mathrm{SCN})_{3}$ polymeric units, $\sigma_{1}=100 \mathrm{erg} / \mathrm{cm}^{2}$ and $M=174 \mathrm{~mol} / \mathrm{g}$. 
The values of $\Delta G^{*}, g^{*}$ were obtained from eqns. (9) and (10) and from the expression of $P_{2}$ and $P_{3}$ defined in eqn. (6), $N_{0}^{\mathrm{I}}$ and $A$ were estimated at a constant potential by taking $D=1 \times 10^{-5} \mathrm{~cm}^{2} / \mathrm{s}, z=1$ and $\rho=2 \mathrm{~g} / \mathrm{cm}^{3}$ [18]. Values of $\omega$ were also derived from eqn. (14) on the assumption that the polymeric unit corresponds to the trimer $(\mathrm{SCN})_{3}$ (Table 3). The low value of $g^{*}$ estimated for the critical cluster might suggest an atomistic approach for interpreting the anodic layer formation.

The increase in temperature decreases $q_{\mathrm{m}}$ and, consequently, the value of $\omega$. Since each nucleus is made up of polymeric units, as the temperature increases to reach the critical conditions for nucleation, a larger number of units should be required. This offers an explanation for the corresponding increase in the $\Delta G^{*}$ value.

Dependence of reaction yields on temperature

Equation (7) can be written as the sum of two independent phase-forming processes $\left(I_{1}\right.$ and $\left.I_{2}\right)$ :

$I=I_{1}+I_{2}=P_{1} P_{2} \exp \left[-\left(P_{2} t+P_{3} t^{2}\right)\right]+2 P_{1} P_{3} \exp \left[-\left(P_{2} t+P_{3} t^{2}\right)\right]$

From eqn. (16) the $I_{1} / I_{2}$ ratio is:

$I_{1} / I_{2}=P_{2} / 2 P_{3} t=N_{0}^{1} / N_{0}^{\mathrm{II}}$

On the other hand, eqn. (7) defines the maximum current $\left(I_{M}\right)$ at the time $t_{M}$ :

$t_{\mathrm{M}}=\left(1 / 2 P_{3}\right)^{1 / 2}-\left(P_{2} / 2 P_{3}\right)$

Then, from eqns. (16) and (17) the $I_{1} / I_{2}$ ratio at $t_{\mathrm{M}}$ is given by:

$\left(\frac{I_{1}}{I_{2}}\right)_{t_{\mathrm{M}}}=\frac{P_{2}}{2 P_{3} t_{\mathrm{M}}}=\frac{P_{2}}{\left(2 P_{3}\right)^{1 / 2}-P_{2}}$

and, accordingly:

$S_{\text {ext }}=S_{\text {ext }}^{1}+S_{\text {ext }}^{\mathrm{II}}=\frac{1}{2}-\left(P_{2}^{2} / 4 P_{3}\right)$

Within the temperature range investigated, the degree of surface coverage estimated from eqn. (20) at $t_{\mathrm{M}}$ is somewhere between 0.65 and 0.72 . At a constant potential, the dependence of the $I_{1} / I_{2}$ ratio on temperature suggests that the electroformation of $\left[(\mathrm{SCN})_{3}\right]_{x^{\prime}}$ becomes relatively more important in the intermediate temperature range, whereas the formation of the most stable species, $(\mathrm{SCN})_{x}$, is apparently favoured at the extreme temperatures. On the other hand, at a constant temperature, the $I_{1} / I_{2}$ ratio increases with $E_{\mathrm{s}}$. This means that the contribution of $(\mathrm{SCN})_{x}$ formation is also favoured at sufficiently positive $E_{\mathrm{s}}$ values.

In conclusion, the interpretation of the potentiostatic transients related to the electro-oxidation of molten thiocyanates confirms the validity of a complex mechanism containing various reaction pathways with the participation of electrochemical and chemical reactions over the entire range of temperature and applied potential 
conditions yielding two main solid products $[8,10]$. From the mechanistic standpoint, the overall anodic reaction can be understood as a linear combination of two solid phase nucleation and growth processes both under diffusion control. From the standpoint of the overall reaction, the possibility of minor electrochemical decomposition of the anodic products into $\mathrm{S}_{x}$ and $(\mathrm{CN})_{2}$ should also be considered [1,2], especially at the highest temperatures, although a minor contribution of this process does not essentially modify the basic approach of the reaction mechanism discussed above.

\section{ACKNOWLEDGEMENTS}

INIFTA is a Research Institute jointly established by the Universidad Nacional de La Plata, the Consejo Nacional de Investigaciones Científicas y Técnicas and the Comisión de Investigaciones Científicas de la Provincia de Buenos Aires. This work was partially supported by the Regional Program for the Scientific and Technological Development of the Organization of the American States. V.D.V.M. thanks the Universidad de Concepción (Chile) for a leave of absence and DAAD for the fellowship granted through the Cooperation Agreement between the University of Mainz (Germany) and the University of La Plata (Argentina).

\section{REFERENCES}

1 A. Eluard and B. Trémillon, J. Electroanal. Chem. 13 (1967) 208.

2 G. Metzger, Rapport C.E.A., No. R 2566, Centre d'Etudes Nucléaires, Saclay, 1964.

3 R.E. Panzer and M.J. Schaer, J. Electrochem. Soc., 112 (1965) 1136.

4 K.F. Denning and K.E. Johnson, Electrochim. Acta, 12 (1967) 1391.

5 A.J. Calandra, M.E. Martins and A.J. Arvia, Electrochim. Acta, 16 (1971) 2057.

6 B. Cleaver, A.J. Davies and D.J. Schiffrin. Electrochim. Acta, 18 (1973) 747.

7 A.J. Arvia, A.J. Calandra and M.E. Martins, Electrochim. Acta, 17 (1972) 741.

8 F. Pucciarelli, P. Cescon and M. Heyrovský, J. Electrochem. Soc., 126 (1979) 972.

9 C. Martinez, A.J. Calandra and A.J. Arvia, Electrochim. Acta, 17 (1972) 2153.

10 F. Pucciarelli, P. Cescon, F. Diomedi-Camassei and M. Heyrowský, J. Chem. Soc., Chem. Commun., (1973) 154.

11 M. Fleischmann and H.R. Thirsk in P. Delahay and C.W. Tobias (Eds.), Advances in Electrochemistry and Electrochemical Engineering, Vol. 3, Interscience, Chichester, 1963.

12 A. Bewick and M. Fleischmann in E. Kay and P.S. Bagus (Eds.), Topics in Surface Chemistry, Plenum Press, New York, 1978, p. 45.

13 G.J. Janz, Molten Salts Handbook, Academic Press, New York, 1967.

14 R. Pereiro, A.J. Arvia and A.J. Calandra, Electrochim. Acta, 17 (1972) 1723.

15 S.K. Rangarajan, Faraday Symp. Chem. Soc., 12 (1978) 101.

16 M. Avrami, J. Chem. Phys., 1 (1939) 1103; 8 (1940) 212; 9 (1941) 177.

17 U.R. Evans, Trans. Faraday Soc., 41 (1945) 365.

18 E. Bosco and S.K. Rangarajan, J. Chem. Soc. Faraday Trans. 1, 77 (1981) 483, 495. 